\title{
Block copolymer membranes for aqueous solution applications
}

\author{
Suzana Pereira Nunes* \\ King Abdullah University of Science and Engineering (KAUST), \\ Biological and Environmental Science and Engineering Division (BESE), \\ 23955-6900 Thuwal, Saudi Arabia
}

*Corresponding author:

Suzana Nunes

King Abdullah University of Science and Technology (KAUST)

suzana.nunes@kaust.edu.sa 


\begin{abstract}
Block copolymers are known for their intricate morphology. We review the state of the art of block copolymer membranes and discuss perspectives in this field. The main focus is on pore morphology tuning with a short introduction on non-porous membranes. The two main strategies for pore formation in block copolymer membranes are (i) film casting and selective block sacrifice and (ii) self-assembly and non-solvent induced phase separation (SNIPS). Different fundamental aspects involved in the manufacture of block copolymer membranes are considered, including factors affecting the equilibrium morphology in solid films, self-assembly of copolymer in solutions and macrophase separation by solvent-non-solvent exchange. Different mechanisms are proposed for different depths of the SNIPS membrane. Block copolymer membranes can be prepared with much narrower pore size distribution than homopolymer membranes. Open questions and indications of what we consider the next development steps are finally discussed. They include the synthesis and application of new copolymers and specific functionalization, adding characteristics to respond to stimuli and chemical environment, polymerization-induced phase separation, and the manufacture of organic-inorganic hybrids.
\end{abstract}




\section{Introduction}

Membrane technology is now well established for different water-based separations. Reverse osmosis (RO) is the predominant technology for desalination of seawater. In the Middle East many RO desalination plants operate with water supply higher than $200,000 \mathrm{~m}^{3} /$ day, using mainly flat sheet thin film composite membranes, constituted by porous asymmetric layers of polysulfone, coated by interfacially polymerized polyamide selective layers or cellulose acetate membranes in the form of thin porous hollow fibers. In the biomedical field, polymeric hollow fiber membranes are key components of hemodialyzers, or artificial kidneys, which save life of more than 2.5 million patients in constant treatment worldwide. In spite of the already accomplished success, new polymeric materials could extend the membrane application to other separations. This would require more appropriate surface chemistry and structuration, better defined pore morphology with narrower pore size distribution, additional functionalities and stimuli-response properties, which are not offered by classical homopolymer membranes.

Block copolymers have been much less used for membrane applications than homopolymers, but they are opening new perspectives in the field and could overcome some drawbacks of homopolymer membranes. They can be applied as non-porous coatings or as porous films, hollow fibers and particles. We start this manuscript with a summary of the pioneering approaches and selected potential future developments using block copolymers for non-porous membranes and coating, targeting water-based applications. The versatility of morphology control and the possibility of having a much narrower pore size distribution and high porosity are the largest advantages of block copolymers for membrane manufacture. These are the main focus of this manuscript. The main aspects guiding morphology in block copolymer membranes are discussed. We summarize the expected thermodynamic equilibrium morphologies and the variety of self-assemblies in solution. We discuss how it is possible to control the final pore morphology and what are the open questions and perspectives of further development in the field.

The two main strategies for pore generation in block copolymer membranes are (i) film casting and selective block sacrifice and (ii) self-assembly and non-solvent induced phase separation (SNIPS), a process depicted in Figure 1. We consider SNIPS the most promising technology, being a fast and scalable manufacture process. The technical production would require instrumentation similar to those already used for industrial membrane fabrication. For this reason the different steps and mechanisms involved in SNIPS are discussed with more detail, as well as the most recent developments and suggestions for future work. 

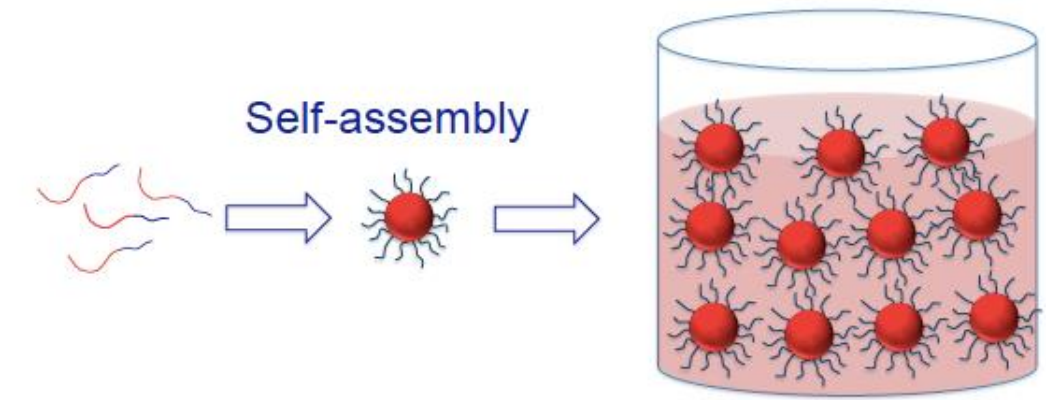

Immersion in water
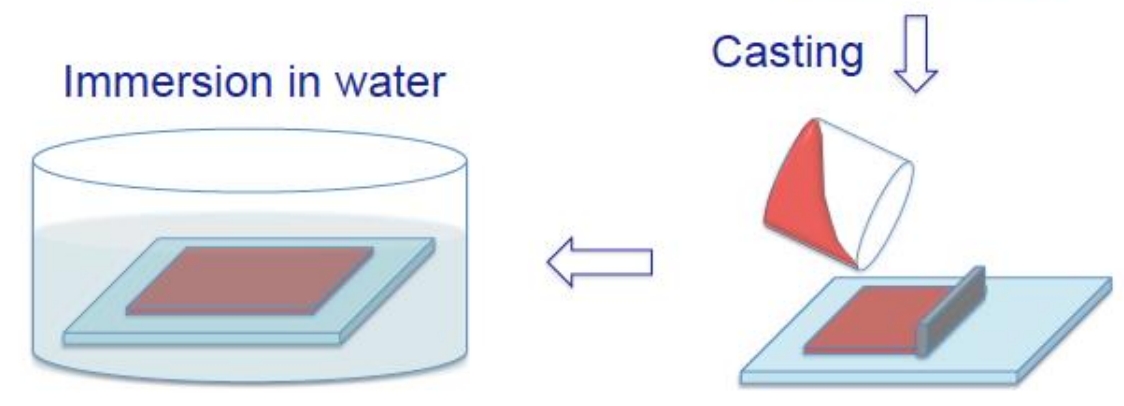

Figure 1. Block copolymer self-assembly, casting and immersion in non-solvent bath (SNIPS process).

\section{Non-porous block copolymer membranes and coatings}

Lyman et al. ${ }^{1,2}$ were probably the first to report on block copolymer membranes. They developed synthetic membranes from poly (ethylene oxide) (PEO) and poly (ethylene terephthalate) block copolymer for blood dialysis. These were dense membranes and the block morphology was less relevant in this initial development. They were looking for higher selectivity for dialysis, by combining the proper ratio of hydrophilic and hydrophobic segments. Separation was driven by selective solubilization and diffusion. Polyether constitutes one of the blocks of PEBAX $^{\circledR}$, a commercial polyether- $b$-polyamide copolymer. We reported the first dense hydrophilic membranes for ultrafiltration based on PEBAX ${ }^{\circledR}$, characterized by low fouling and tested for oilwater separation ${ }^{3}$. While the polyamide block contributes to the mechanical stability of the membrane, even when swollen in water, the polyether block makes the membrane hydrophilic and permeable to water. PEBAX $^{\circledR}$ has been extensively explored for other applications, such as gas separation. The polyether block strongly interacts with $\mathrm{CO}_{2}$ and these membranes have been successfully used for $\mathrm{CO}_{2}$ separation from other gases ${ }^{4,5}$. PEBAX $^{\circledR}$ is available with different block lengths and slightly different block composition, which allows tuning membrane selectivity for solvent separations with different polarity. Dense block copolymer membranes based on PEBAX ${ }^{\circledR}$ have been early explored for dehydration and solvent elimination from aqueous feeds by pervaporation ${ }^{6}$.

Charged block copolymers have been explored for the manufacture of fuel cell membranes. ${ }^{7,8}$ They offer the possibility of controlling swelling and electrosmotic transport, while keeping proton conductivity high. Details on fuel cell membranes are 
out of the focus of this paper. Charge mosaic is a different kind of charged membrane, which is still in a fundamental stage of development It constitutes a challenging opportunity for block copolymers. These membranes have alternating nanosize domains with opposite charges ${ }^{9-12}$. This gives them the capability of being more permeable for salt than for small neutral molecules 10, 13, 14, as shown in Figure 2. Charge mosaic membranes were among the first reported block copolymer membranes $9,10,13-15$. Miyaki et al. 9, 15 prepared charge mosaic membranes from a pentablock copolymer, polyisoprene- $b$-polystyrene- $b$-polyisoprene- $b$-poly(4-vinylbenzyl) dimethylamine- $b$ isoprene), with one block being quaternized, another sulfonated and one of the other blocks used for crosslinking. Analogous commercial pentablock copolymers (NEXAR $\left.{ }^{\circledR}\right)$ have been recently rediscovered and explored, not as charge mosaic, but for other applications 16-18. Progresses on charge-mosaic membranes after the first reports have been limited and were recently reviewed ${ }^{19}$.

Block copolymers could have a significant contribution to other kind of emerging non-porous membranes, having biomimetic channels. The most prominent approach involves the incorporation of aquaporin into vesicles ${ }^{20-24}$ and flat-sheet membranes ${ }^{25}$, as shown in Figure 2, with the expectation of achieving exceptional high water fluxes, similar to those obtained in biological systems. However there are still many issues to be solved. Besides cost and availability of aquaporin in large scale, a critical issue is the incorporation in the membrane with acceptable stability. The role of block copolymers so far has been as facilitators ${ }^{26}$ for protein insertion in the membranes, as in Figure 2. Comprehensive reviews on biomimetic and bioinspired membranes have been recently published 27,28 . Probably more promising, at least in terms of stability and scalability, is the membrane development with bioinspired channels, but completely constituted by artificial, synthetic amphiphilic copolymers.

A final application to be mentioned as non-porous block copolymer coatings is fouling minimization. Fouling is one of the most common issues in water treatment. It is the deposition of organics or growth of biofilms (biofouling) on the membrane surface, leading eventually to pore blocking, with serious consequences of flux decrease under operation. Block copolymers have been used to effectively modify membrane surfaces. Cho et al. ${ }^{29}$ synthesized amphiphilic copolymers with side chains of hydrophilic PEO blocks and hydrophobic blocks of polystyrene (PS) and polyisoprene (PI) with clear decrease of the number of attached microalga and diatom cells as the PEO content of increased. A similar approach using ethoxylated fluoroalkyl side chains were previously used with success ${ }^{30,31}$. Copolymers with zwitterionic segments have been explored by other groups. They have been tethered on reverse osmosis membranes ${ }^{32}$, as brush block copolymers with quaternary ammonium and zwitterionic segments, started from polydopamine layers, applied on thin-film composite membranes ${ }^{34}$. Zwitterionic random copolymers have been applied for membrane fabrication. ${ }^{33}$ Fouling-resistant poly(vinylidene fluoride) (PVDF) membranes have been developed by Liu et al. ${ }^{35}$ using amphiphilic block-like copolymer bearing hydrophobic poly(butyl methacrylate), hydrophilic PEG- $b$-(methyl ether methacrylate) and low surface energy poly(hexafluorobutyl methacrylate) segments as additive in the membrane preparation. The elegant approaches could contribute to minimize the early stages of the complex 
fouling mechanism. In long-term operation in large-scale water treatment and purification applications fouling might still remain a challenging problem.

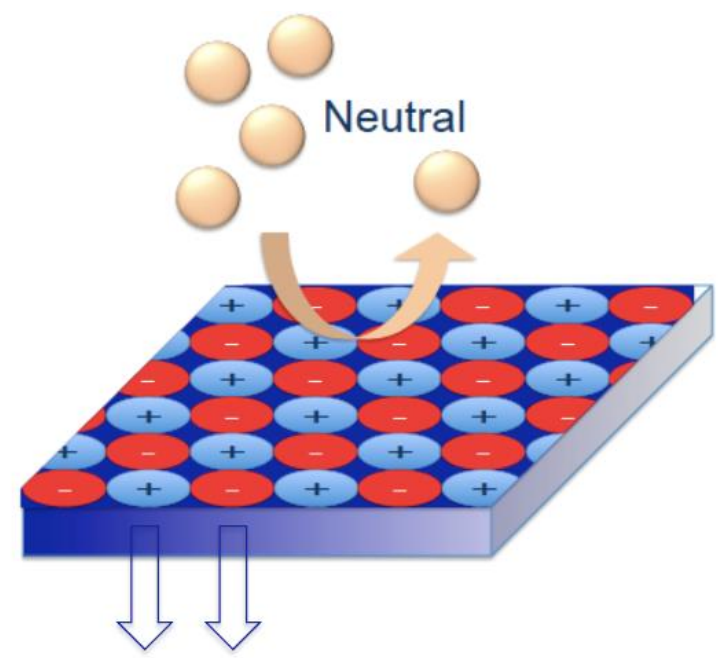

$\mathrm{Na} \mathrm{Cl}$

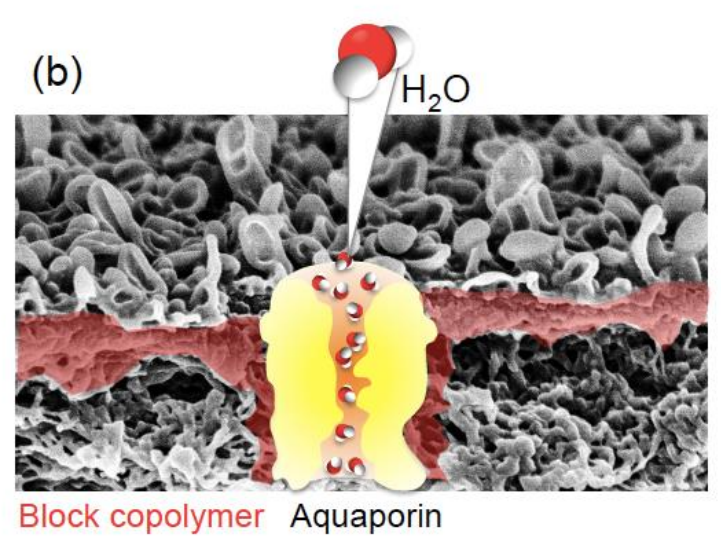

(b)

Figure 2. Dense membranes: (a) charge mosaic and (b) biomimetic membrane with embedded aquaporin surrounded by block copolymer layer.

\section{Porous block copolymer membranes: the advantage of unique morphologies}

What makes block copolymer unique for the preparation of porous membranes is the great variety of morphologies, which can be tuned in the nano-scale. There are different aspects for consideration, when choosing the right copolymer and conditions for membrane preparation. The thermodynamic aspects of block copolymer morphology in equilibrium will be first discussed in this session. Most membrane manufacturing processes are based on solution and the final morphology is in most cases a nonequilibrium, kinetically trapped structure. Considerations on self-assembly in solution, as well as mechanisms of macrophase separation, which are essential for the SNIPS process, will be discussed here.

\section{Equilibrium morphology in the melt.}

The order-disorder transition of block copolymers and the rich variety of morphologies in equilibrium in the melt have been extensively reported, as summarized in Figure 3. For diblock copolymers, going from asymmetric to symmetric block ratios, spherical (S) domains, cylinders (C) and lamellae (L) have been the most commonly observed and have been revised in excellent reports in the field ${ }^{36-43}$. The free energy cost of having immiscible $\mathrm{A}$ and $\mathrm{B}$ blocks together in the melt is estimated ${ }^{37}$ by taking into account the Flory-Huggins interaction parameter, $\chi_{\mathrm{AB}}$, the degree of polymerization, $\mathrm{N}$, 
and the entropic restriction, when the blocks are stretched or the elastic free energy. By considering the size fraction of each block, $\mathrm{f}_{\mathrm{A}}=\mathrm{N}_{\mathrm{A}} / \mathrm{N}$, the kind of morphology expected in the equilibrium can be estimated for a simple diblock copolymer system. Small copolymer blocks with low $\chi_{\mathrm{AB}} \mathrm{N}$ value $(<10.5)$ should not follow a microphase separation; above that if $\mathrm{f}_{\mathrm{A}}=0.5$, for symmetrical copolymers, lamellar structure is expected; if $f_{A}>0.5$, cylinders of smaller $B$ blocks are favored or spheres if $f_{A}$ is even larger. The curvature allows the molecules to balance the degree of stretching between the A and B blocks. Particularly the cylindrical structures offered by diblock copolymers are attractive for membranes if they are orthogonal to the surface. For triblock copolymers in the melt even richer morphology has been early demonstrated by different groups $41,44-48$.

(a) Equilibrium morphologies

(b) Metastable morphologies

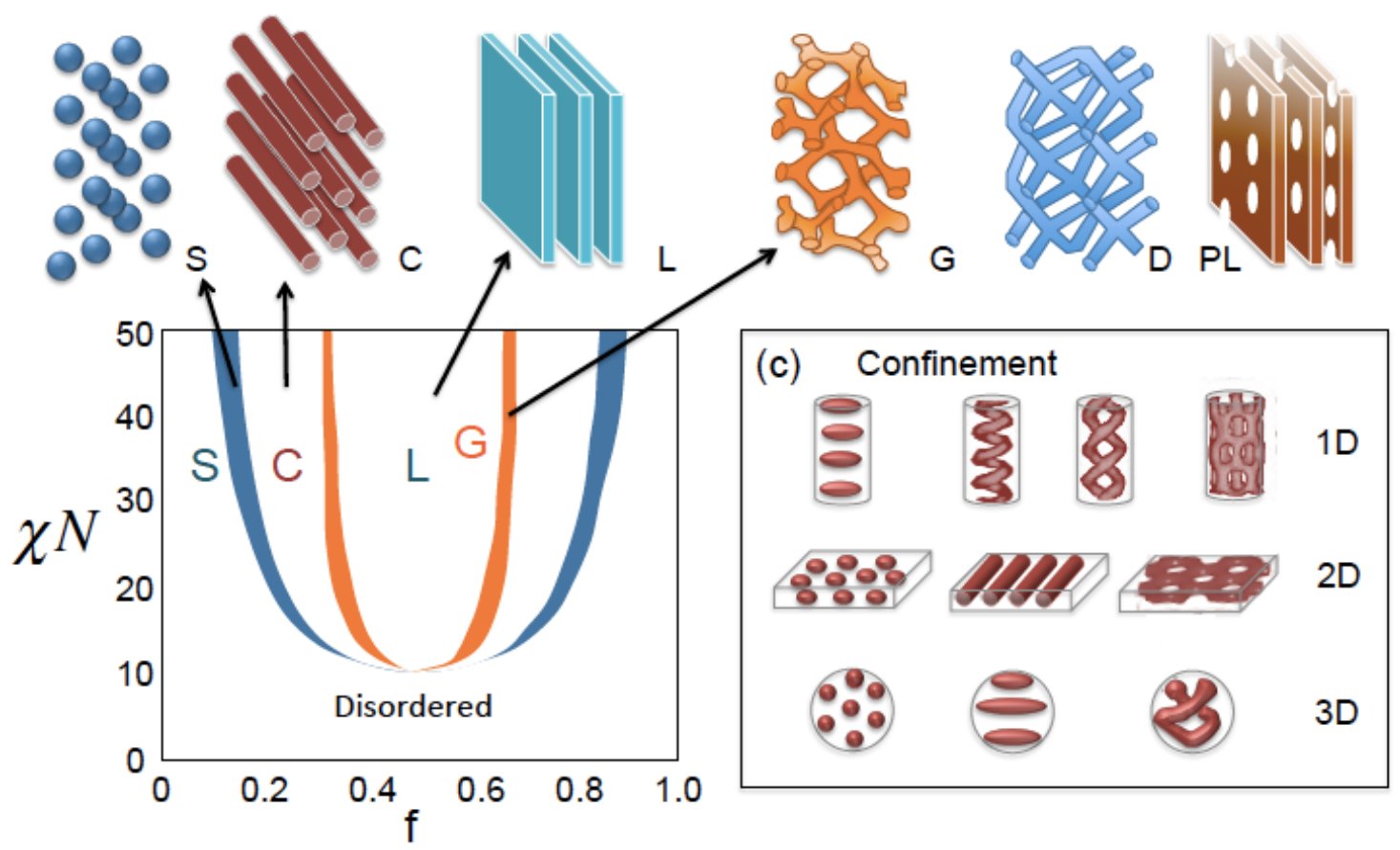

Figure 3. Diblock copolymers in melt: (a) equilibrium morphology; (b) metastable morphology; (c) morphology under confinement, based on previous work ${ }^{37,40,49-51}$.

Additional more complex bicontinuous network morphologies, periodic and with minimized interfacial area, are gyroid (G) and bicontinuous double diamond (D) structures. They have been demonstrated by Thomas's group in the 80 's ${ }^{52,53}$ for star block copolymers, diblock copolymer/homopolymer blends and triblock copolymers 41,54 , 55 . The interconnected structures would be ideal candidates for membrane application if they could be prepared in an easily controlled and scalable way. Recently this possibility was theoretically revived by Erukhimovich et al. ${ }^{56}$

Scriven ${ }^{57}$ proposed that bicontinuous morphologies, with each phase connected across the system, can arise in fluids. He described them for microemulsions, for systems with swollen micelles, close to conditions, which favor micelle inversion or matrixdomain emulsion inversion. These structures resemble triply periodic minimal surface 
with practically no mean curvature, under conditions that favor the fusion of dispersed spheres over separated ones. They particularly satisfy the Young-Laplace equation for menisci between immiscible bulk phases coexisting at the same hydrostatic pressure. Thomas et al. ${ }^{53,58}$ pointed out that some of the block copolymer co-continuous morphologies observed in the melt are related to minimal surfaces. At least some structures with constant mean curvature evolve from close packing of spheres, as shown by Scriven ${ }^{57}$ (Figure 4). Periodic area-minimization surfaces are considered metastable and seen as transitions between equilibrium phase-separated structures. Triply periodic surfaces and the interplay of bending energy and vesicles adhesion have been correlated to the morphology of biological membranes ${ }^{59}$ and liposomes ${ }^{60}$.

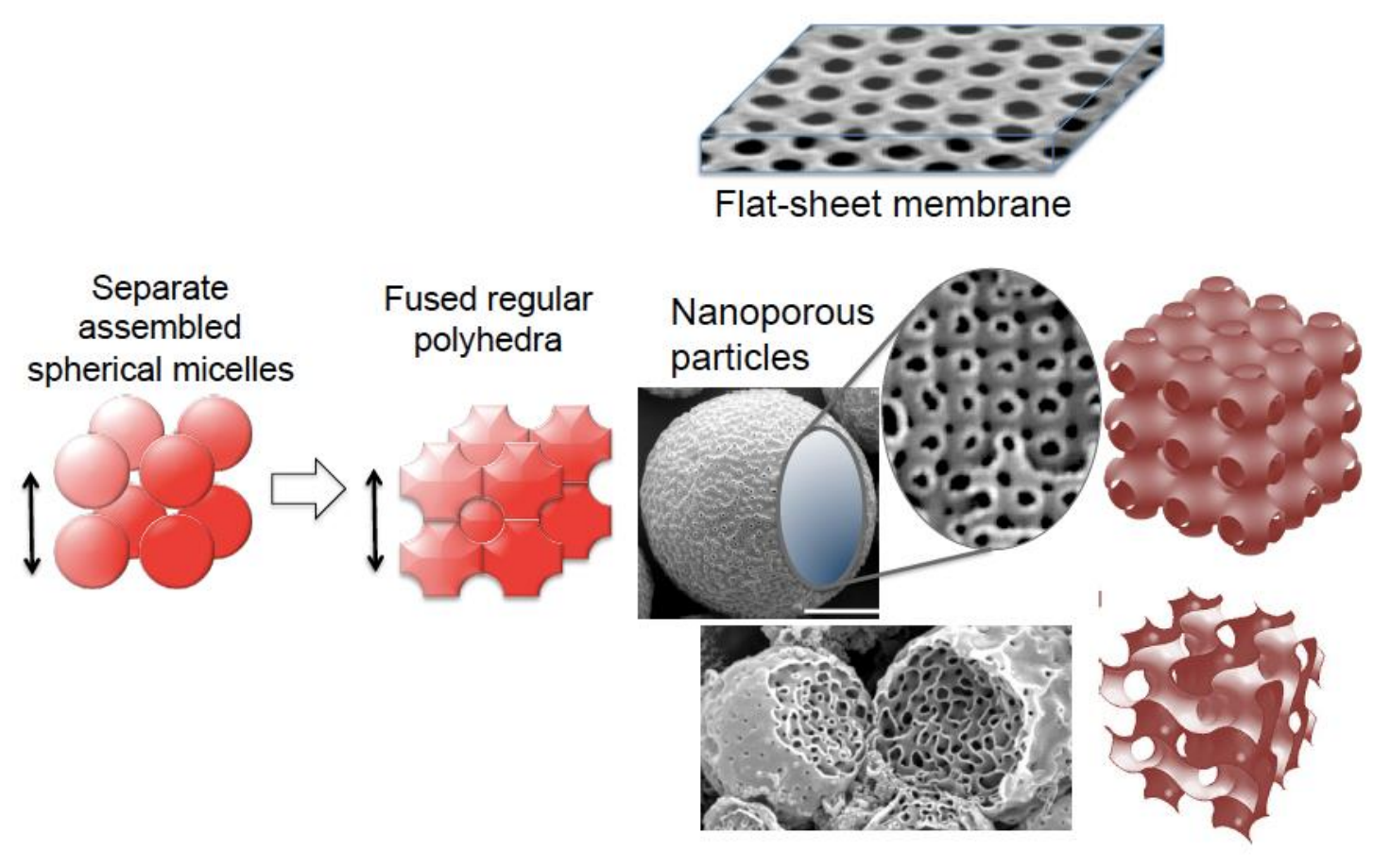

Figure 4. Micelles partial fusion, forming morphologies structurally related to minimal surface, as described by Scriven ${ }^{57}$ and examples of periodic structures observed for block copolymer porous membranes and particles ${ }^{61-63}$.

Another complex structure, which might be relevant for membrane formation is the perforated lamellae (PL), occurring when the minority-component layers of the $\mathrm{L}$ phase develop a hexagonal arrangement of wholes or passages ${ }^{64-67}$. More complex structures such as gyroid, double diamond $52,53,58$ or perforated lamellae were not predicted in the pioneer works on self-consistent mean-field theory (SCFT) ${ }^{36,68}$ proposed for block copolymers. The morphologies have been later identified in systems considered of weak to intermediate segregation strength. Thomas et al. ${ }^{69}$ emphasized the role of the interfacial tension in block copolymer morphology with structures adopting areaminimizing surfaces of constant mean curvature packing frustration. Periodic morphologies in block copolymers are strongly influenced by a competition between interface shape and chain-packing conformation ${ }^{70}$. PL is sometimes observed near the 
L/G phase boundary as metastable state. Packing frustration is believed to prevent the stability of PL phases in general in the strong-segregated systems, but they have been reported in many cases particularly when confinement is present ${ }^{71}$. Interesting work on PL formation in (thin) films of different thicknesses has been published by Krausch's group ${ }^{65,67}$. They reinforce that although not considered an equilibrium phase in the bulk, PL could be stabilized by surface interactions. Normally the most general case is that if the surface has a preferential interaction for one of the blocks, there is a surface induced orientation, with microdomains (e. g. cylinders) parallel to the surface. In thin films this orientation might come with a free energy penalty due to chain stretching in the parallel morphology. If there is no strong enthalpic motivation for surface preferential wetting, the largest block tends to accumulate on the surface and an entropic balance will guide the placement of the smaller block. Cylinders to lamellae or cylinder to perforated transitions are then promoted ${ }^{72}$. The predictions were focused on thin films, but do not exclude the occurrence in thicker systems. Therefore under specific conditions the normally metastable perforated lamellae phase can be stabilized. The equilibrium morphology under different confinements can substantially change. Besides the 2D block copolymer confinement (thin film), 1D (cylinders) ${ }^{69,73-75}$ and 3D (spheres) ${ }^{50,76}$ confinements have been more recently discussed. Some examples are shown in Figure 3. We believe the structures observed in the pore formation of block copolymer membranes prepared by SNIPS might be correlated to triply periodic minimal surfaces.

The morphologies, which are expected in thermodynamic equilibrium, shown in Figure 3 are only reached after careful casting in good and common solvents, followed by days of annealing above the glass transition temperature of both blocks. These conditions are not convenient for real application and would be hardly implemented for membrane preparation in the industry. Solvent annealing can be used to reach the equilibrium morphology faster. Additionally it has been used to induce a morphology, which might not correspond to the lowest energy for the solvent-free system, but it would be more attractive to promote connectivity between both sides of the membrane. The induced morphology is than trapped by the low mobility of the system as the solvent is eliminated. Typical example is the alignment of cylinders orthogonally to the surface under the influence of solvents. Morphology tuning by solvent annealing has been reviewed by Hamley ${ }^{39}$ and Albert ${ }^{77}$.

\section{Block copolymers in solution: diversity of self-assembly structures}

Most membrane-manufacturing processes, which are scalable, with demonstrated technological success, include a solution-casting step ${ }^{78}$. When block copolymers solutions are used, self-assembly is a relevant aspect, which can significantly affect the final membrane morphology, depending on the chosen strategy, additionally to aspects regularly considered for homopolymers. The self-assembly of block copolymers in solution is more complex than in the melt, since the thermodynamic interaction between the different blocks and a variety of possible solvents and solvent mixtures have to be taken into consideration. The morphology in solution has been less investigated and theoretical predicted than in the melt. Eisenberg's group ${ }^{79-81}$, Gast ${ }^{82-84}$, Lodge et al. ${ }^{85-87}$ had important contributions to the field, reporting spherical micelles, cylinders or wormlike micelles, vesicles, bicontinuous rods, bilayers and more complex structures, 
which are referred as hexagonally packed hollow hoops. In general in a simplified form, as in Figure 5, the morphology in relatively diluted solution is predicted using the packing parameter, analogously to what is used for surfactants ${ }^{88}$ :

$p=v / a l$

where $v$ is the volume of the solvophobic segment, $l$ its length and $a$ is the contact area of the solvophilic segment. Spherical micelles are expected if $p<1 / 3$; cylinders for $1 / 3<p$ $<1 / 2$; vesicles if $1 / 2<p<1$; lamellae if $p=1$ and inverted structures if $p>1$. Hayward and Pochan ${ }^{89}$, Gröschel and Müller ${ }^{90}$, Armes ${ }^{91,92}$, Smart et al. ${ }^{93}$ have added a variety of rich and complex morphologies and revised the literature on block copolymers in solution. The morphology can be induced by using pre-synthesized copolymers or by direct polymerization in solution ${ }^{92}$ or by metallic ligand binding ${ }^{94}$.
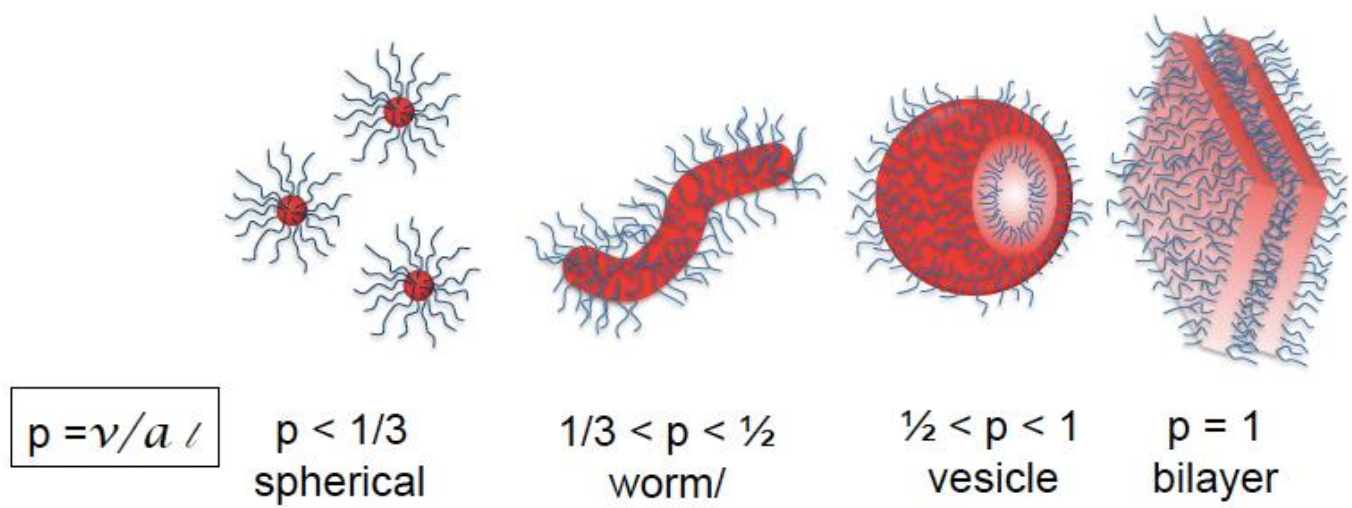
$1 / 3<p<1 / 2$ worm/ micelle

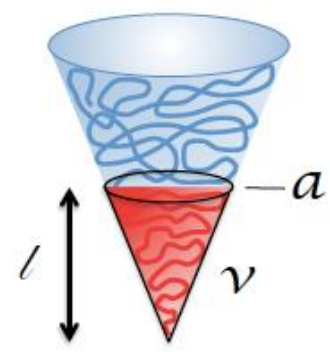
cylinder
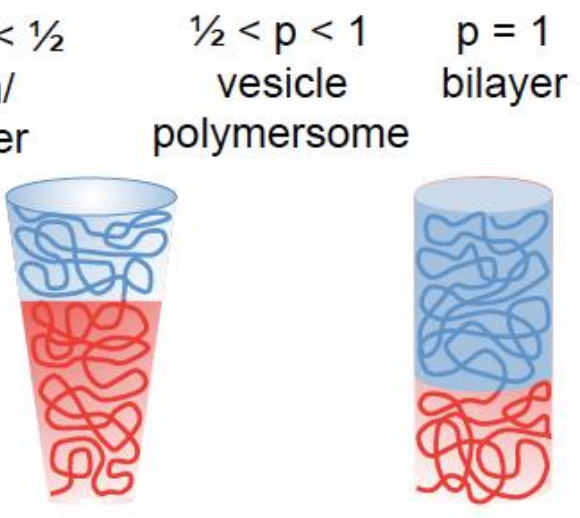

high

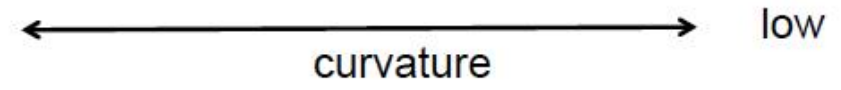

Figure 5. Block copolymer morphologies in solution, based on ${ }^{79,88}$.

The copolymer concentration is an important factor for the morphology. In the range of 10-20\% spherical micelles will order forming a lattice. The lattice geometry depends on copolymer concentration and the solvent-blocks and block-block interactions. Facecentered (fcc) or body-centered cubic (bcc) geometries are possible and the transition between them can be induced by temperature. Lodge et al. reported that softer micelles (hairy) with long-range interactions favor bcc; hard spheres as in the case of crew cut micelles with short-range interactions favor fcc ${ }^{85,86}$. Polymerization induced selfassembly (PISA) ${ }^{95-97}$ is a growing field, which in addition to controlling concentration 
and solvent composition delivers even more diverse morphologies of block copolymers in solution.

Non-solvent induced (macro) phase separation (NIPS): interplay of thermodynamics and kinetics

The NIPS process is applied to most homopolymer membranes available in the market. The process was initially introduced by Loeb and Sourirajan ${ }^{98}$, more than 50 years ago. The macrophase separation and immobilization process is summarized here and illustrated in Figure 6.

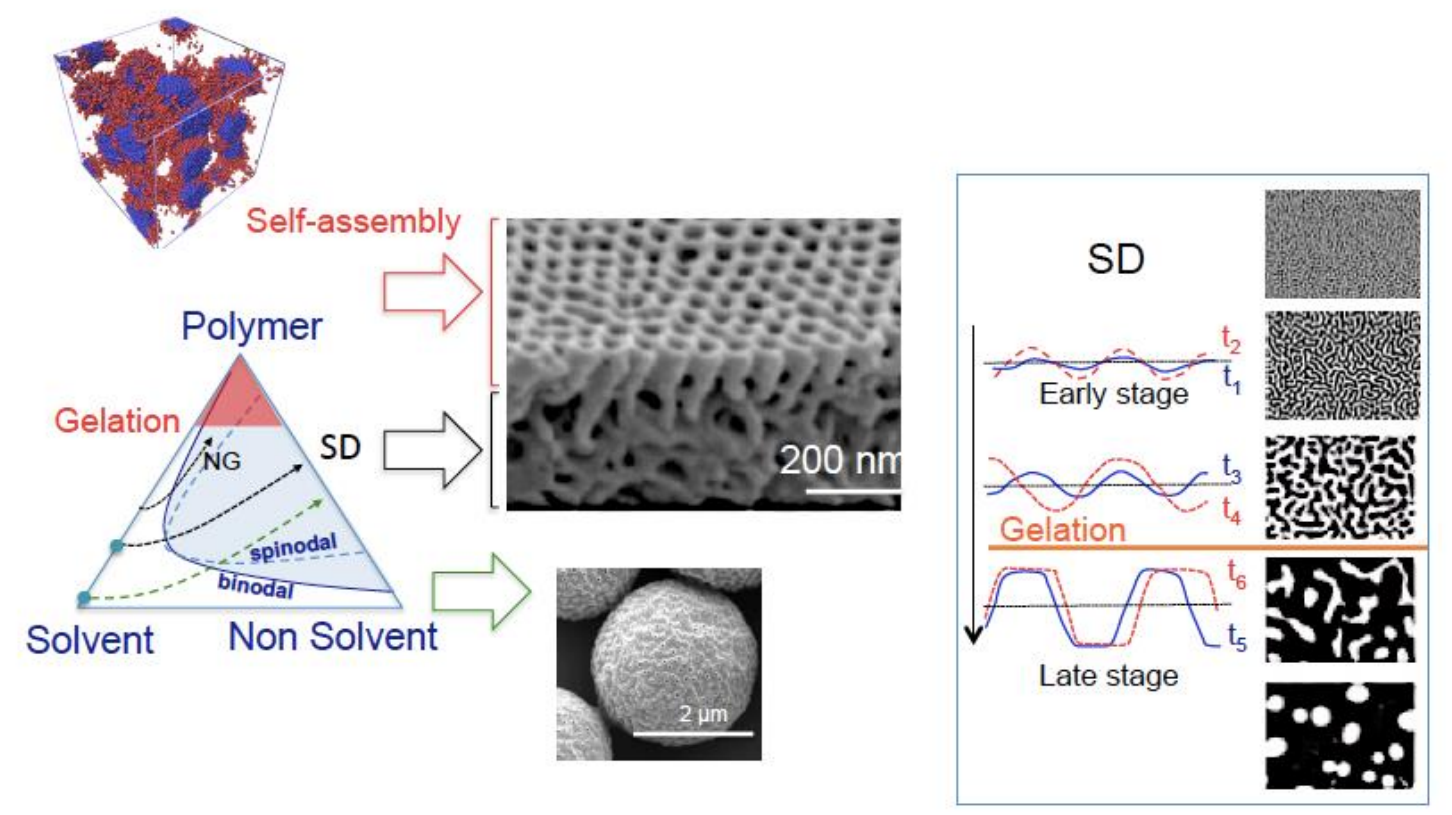

Figure 6. Combination of self-assembly and non-solvent induced phase separation mechanisms in the formation of isoporous flat-sheet membranes (casting solution in the semi-diluted concentration regime) and porous particles (less concentrated starting solution). Examples adapted from previous reports ${ }^{63,78,99,100}$.

Independently of working with block copolymer or homopolymers, the NIPS membrane process involves casting solutions in a semi-diluted concentration range and their immersion in a non-solvent bath, which is in most cases water. Smolder's 101, 102, Strathmann's groups ${ }^{103}$ and later Koros ${ }^{104,105}$ had an important contribution to elucidate the mechanism of pore formation in homopolymer membranes, among other groups. Our group ${ }^{78,106-108}$ discussed in detail the interplay of two phase separation mechanism, nucleation and growth (NG) and spinodal decomposition (SD), in membrane formation, demonstrating the mechanism with thermodynamic simulations ${ }^{107}$ and light scattering ${ }^{106}$, 108 investigation supported by the Cahn theory ${ }^{109}$. The predominance of NG or SD mechanism depends on the path in the phase diagram during water-solvent exchange after immersion in the non-solvent (water) bath (ternary phase diagram in Figure 6). If the thermodynamics conditions abruptly change from one-phase to the two-phase regions, 
SD is initiated. On the other hand, if the thermodynamic conditions favor a long permanence in the metastable region between the binodal and the spinodal curves, nuclei formation and subsequent growth would be predominant. If the starting solution has a concentration in the semi-diluted range, as usual for membrane casting solutions, the phase separation will lead to a more concentrated continuous phase forming the membrane matrix and a diluted phase forming the pores. NG would lead to membranes with closed cell pores, while SD leads to interconnected pores, which are of course those targeted for a good membrane. SD starts with local concentration oscillation whose amplitude increases with time as in Figure 6.

The binodal and the spinodal curves can be thermodynamically predicted from equations describing how the free Gibbs energy of mixing $\left(\Delta \mathrm{G}_{\mathrm{M}}\right)$ varies as a function of the system composition. For a polymer casting solution with $\mathrm{K}$ components, $\Delta \mathrm{G}_{\mathrm{M}}$ per mole of polymer segments ${ }^{107}$ can be estimated by the following equation:

$\frac{\bar{G}}{R T}=\sum_{i=1}^{K} \frac{1}{N_{i}} \quad \ln \quad i+\sum_{i=1}^{K} \sum_{j=i+1}^{K} \quad i j \quad i \quad j$

where $\mathrm{R}$ is the molar gas constant, $\mathrm{T}$ is the temperature; $\varphi_{\mathrm{i}}$ and $\varphi_{\mathrm{j}}$ are the volume fractions of components $i$ and $j$ and $\chi_{i j}$ is the Flory-Huggins parameter between components $i$ and $j$; $\mathrm{N}_{\mathrm{i}}$ is the number of sites occupied in lattice by a molecule $\mathrm{i}$, as normally considered in the Flory-Huggins theory (can be estimated as the molecule molar volume divided by the segment volume). In a system of two coexistent phases in equilibrium, the chemical potential, $\mu_{\mathrm{i}}$, of each component $\mathrm{i}$ is equal in the two phases $\alpha$ and $\beta$ :

$$
{ }_{i}=\frac{\partial(\bar{G} / R T)}{\partial_{i}}
$$

The binodal curve can be then estimated from the free Gibbs energy curve as a function of volume fraction, finding the points with common slope. The binodal curve can be experimentally estimated by cloud point measurements. The spinodal curve delimitates the metastable region in the phase diagram. In terms of Gibbs energy it is calculated by determining the inflection points, for which the second derivative of Eq. 1 is equal to zero:

$\frac{\partial^{2}(\bar{G} / R T)}{\partial_{i}{ }^{2}}=0$ 
The point at which the binodal and spinodal curves meet, the critical point, is characterized by the third derivative of Eq. 1 being equal to zero.

$$
\frac{\partial^{3}(\bar{G} / R T)}{\partial{ }_{i}^{3}}=0
$$

When phase separation initiates in the metastable region, following the NG mechanism, some activation energy is required for nuclei formation. Local concentration oscillations in the instable condition, characteristic of SD, are spontaneous. Once SD is initiated, the process would continue, forming two continuous interconnected phases, which could coalesce at later stages if the process is not stopped by gelation. If the concentration of one of the continuous phases is high enough, the viscosity increases leading to physical gelation. This is important, since gelation would define at which stage the phase separation stops, kinetically trapping the corresponding morphology. The SD macrophase separation in the case of block copolymer forms a rather disordered asymmetric sublayer, analogous to that obtained in homopolymer systems. This layer provides the mechanical stability of the membrane. If the starting polymer solution is dilute, isolated particles might be formed instead of self-standing flat-sheet membranes. Depending on the thermodynamic conditions, these particles can have high porosity. In block copolymer systems they can be characterized by exceptional order ${ }^{63}$.

\section{SNIPS process}

In the two previous sections we emphasize (i) the richness of the morphology of block copolymer assemblies in solution and (ii) how macrophase separation of polymer solutions, induced by solvent-non-solvent exchange, can be useful to immobilize nonequilibrium structures and form asymmetric porous structures. The idea of combining block copolymer self-assembly and the classical process of membrane preparation, industrially applied to homopolymers, by solution casting and immersion in a non-solvent bath, is depicted in Figure 1 and 6. The basic concept was introduced by Peinemann et al. ${ }^{110}$ as a simple method for preparing porous block copolymer membranes with long range order, without need for etching or preferential dissolution of additives. Despite the simplicity of process, the mechanism of pore formation is rather complex. Only years after the first report the method could be reproduced with different copolymer batches and solvents then with better understanding of how the morphology develops. By using field emission scanning microscopy, focus ion beam and cryo transmission electron microscopy ${ }^{61,111}$ we claimed for the first time that the micelle formation in solution is essential for the membrane formation in this case. Later this has been recognized by other excellent groups in the field ${ }^{112}$. Since then we were dedicated to obtain a comprehensive understanding of the mechanism, which could be summarized based on experimental evidences from previous papers of our group 62,99,111,113, and in collaboration with Wiesner's ${ }^{113,114}$ and Phillip's ${ }^{114}$ groups. This was supported by theoretical work based on dissipative particle dynamics (DPD) ${ }^{99,115}$ simulation. The main relevant aspects will be discussed below, recognizing that there are still open questions, which justify additional investigation. 
The membrane prepared by the SNIPS process is practically constituted by 3 different layers: (i) disordered sublayer ( $>20$ micrometer bottom layer), (ii) ordered selfassembled layer (up to $400 \mathrm{~nm}$ middle layer) and (iii) top surface layer (<100 nm). Each of these layers has preferential contributions of different mechanisms, which act in synergism to form the membrane.

(i) Disordered sublayer. The sublayer is shaped by macrophase separation, preferentially guided by spinodal decomposition (SD) as detailed explained for membranes obtained from homopolymers ${ }^{106,108}$. The contribution of spinodal decomposition has been early clearly discussed by our group ${ }^{99,111}$. SD has been recognized by other groups as a component of the mechanism, for instance by Stegelmeier et al. ${ }^{116}$. SD alone does not explain the formation of the very ordered top layer. It applies to the bottom layer, which has pores of larger size and broader size distribution.

(ii) Ordered Self-assembled layer. The membrane morphology on the upper $400 \mathrm{~nm}$ of the membrane, depicted in Figure 6, is clearly different than that of the asymmetric thicker sublayer. We should differentiate this ordered part as constituted by a very thin surface layer, which we discuss in the next paragraph, and an ordered self-assembled middle layer, which reflects the fingerprint of the block copolymer order in solution and whose formation is discussed here. Solutions used for membrane casting are in the semidiluted range (18 to $25 \mathrm{wt} \%$ ). The solvents are selective for one of the blocks, favoring micelle formation, following the rules summarized in Figure 5. The role of micelles in the membrane formation was first identified by our group ${ }^{111}$. Their presence and assembly in the solution bulk before casting has been directly confirmed by cryo transmission

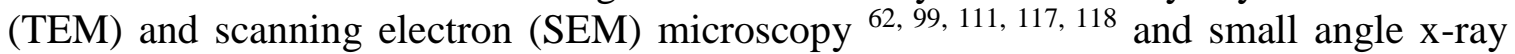
scattering (SAXS) of the casting solution ${ }^{99,113,114}$. Indications that the micelle structures remain as part of the ordered top layer of the membrane were presented by different groups ${ }^{61,111,112}$, using scanning (SEM) or transmission (TEM) electron microscopy, with tomography, scanning transmission electron microscopy (STEM) and focus ion beam (FIB). It is important to mention that the block copolymer assembly in solution is very sensitive to concentration and solvent quality. Therefore observations done in conditions other than those used for membrane casting could lead to misleading conclusions, without a comprehensive understanding of the whole process. For instance conclusions taken with $5 \%$ copolymer in dimethylformamide and water ${ }^{118}$ are far from real conditions of membrane preparation (18-25 wt \% in mixed organic solvents). Changes in copolymer concentration and solvent composition change the morphology and most favorable order for isopores formation occurs in a relatively small window of composition ${ }^{99,116}$. It is clear that the self-assembly of block copolymers into micelles in the casting solution and their supramolecular assembly in a lattice order could be verified 99, 114. It was observed that for diblock and triblock copolymers the final membrane surface morphology (hexagonal or bcc) reflected the morphology encountered in solution. Lodge et al. ${ }^{85,86}$ described the factors favoring fcc or bcc lattice arrangements in solutions in the semi-diluted range, which contain micelles. They demonstrate that softer micelles favor bcc morphology. Softening could be promoted by solvent interaction and infiltration into the corona (and even core, depending on the condition) ${ }^{62}$ 
or by adding a softer segment to the copolymer backbone ${ }^{114}$. This could explain why bcc morphology has been favored with the introduction of a third isoprene block to PS- $b$ P4VP diblock copolymers, while the diblock leads to hexagonal order in similar conditions. We clearly observed ${ }^{62}$ that solvent mixtures such as tehydrofuran/dioxane or dimethyl formamide/dioxane, which swell PS- $b$-P4VP micelles in solution, lead to deformation and poorly ordered membranes. We observed that the addition of hydroxylsubstituted anthracene molecules increases the rigidity of PS- $b$-P4VP micelles and promotes hexagonal order ${ }^{119}$. Rigid micelles could have a behavior closer to star copolymers ${ }^{120}$ or hairy nanoparticles with inorganic core ${ }^{121,122}$, but in opposite to those, they would still be able to deform or fuse, if the thermodynamic conditions allow it. By immersion in water a fast solvent exchange takes place, particularly in the layer close to the solution-water interface, leading to abrupt changes in the thermodynamic conditions with consequent gelation and kinetic trapping of the self-assembly morphology.

(iii) Surface layer. While the ordered layer discussed above is mainly formed by selfassembly in the bulk, the surface pore morphology $(<100 \mathrm{~nm})$ is probably affected by additional air (vapor)-solution interface effects. Time-resolved experiments indicated that the pores might start to be formed on the membrane surface even before the immersion in water, in the case of block copolymer SNIPS process ${ }^{113}$. We froze the membrane in liquid nitrogen after different casting/evaporation times and imaged them by cryo scanning electron microscopy. We followed the evaporation with grazing incidence small angle x-ray scattering (GISAXS). It is possible that the upper layer close to the surface is affected by factors analogous to those leading to the formation of metastable surface morphology in confined systems, related to triply periodic minimum structures, having constant mean curvature. Complex metastable structures were previously observed in selected thermodynamic conditions, but they would disappear if the solvent completely evaporates. In case of SNIPS process, they are kinetically trapped by immersion in water. The structure formation can be understood, by following the discussion proposed by Scriven ${ }^{57}$ for emulsions. As shown in Figure 4, when spheres are closely distributed in a regular lattice, under certain conditions their partial fusion into periodic structures might be more favored with constant mean curvature. In the case of emulsions this is more favored in systems close to their phase inversion composition. As discussed by Krausch et al. ${ }^{65,67}$ for block copolymers in the melt, perforated lamellae could be favored if order is present in the bulk and none of the blocks has a strong preferential tendency to wet the surface. They could have a role in the formation of the commonly observed periodic morphology on the flat block copolymer membrane surface ${ }^{113}$. Other forms of complex periodic surface morphology have been predicted for $3 \mathrm{D}$ confinements ${ }^{50,76}$. Very regular structures (similar to Schwarz $\mathrm{P}$ and Schoen Gyroid) have been observed in porous spherical particles prepared by dispersing block copolymer solutions under stirring in large amount of non-solvent medium ${ }^{63}$. The regular bicontinuous structure in the spherical particles could be comparable to those in 3D confined systems. Polymer dispersions of PEO- $b$-poly(octadecyl methacrylate) nanoparticles with regular bicontinuous porous structures depending on block size have been recently reported by first dissolving in THF followed by addition of water ${ }^{123}$. The contribution of surface aspects on the pore formation is so far the least understood part of the mechanism. 


\section{Porous membranes with block sacrifice}

Apart from the SNIPS process, a number of creative and elaborated approaches have been proposed in the three last decades to obtain porous films starting from block copolymer self-assembly morphology, followed by etching or partial dissolution of additives, as in Figure 7. A pioneer work has been published by Lee et al. ${ }^{124,125}$, who prepared dense block copolymer films containing isoprene (I), which were then cleaved by exposure to ozone to generate pores, while the other block phase was crosslinked. Ozonolysis of isoprene blocks was later used ${ }^{126}$ to promote porosity to PS- $b$-PI films.

Plasma etching was used to selectively remove poly (methyl methacrylate) (PMMA) blocks from films of PS-b-PMMA ${ }^{127}$. Park et al. ${ }^{128}$ used reactive ion etching on PS- $b$ P4VP after gold incorporation in the pyridine blocks on silicon substrate. Russell's group 129 proposed UV-induced degradation of PMMA blocks to prepare porous films. Hillmyer's group has proposed different ways to use PS- $b$-poly (lactic acid) (PS- $b$-PLA) for membrane preparation, by tuning self-assembly and sacrificing the PLA blocks by etching with alkaline solutions 130 131,132. The approaches are summarized in an excellent review, which discuss perspectives of block copolymer membranes ${ }^{133}$. Particularly innovative is the use of block copolymers in the interfacial polymerization (IP) layer for thin film composite membranes, as introduced by Hillmyer's group ${ }^{134}$. As in other papers of his group the PLA block was etched out, but in this case an ultrathin layer is formed combining high flux and selectivity. The method is well scalable, using technology analogous to that applied in the industry for the production of reverse osmosis membranes. The incorporation of block copolymers into the IP layer has not been explored so far by other groups and opens a variety of possibilities to be explored. The approach of controlled polymerization-induced microphase separation is also interesting 135. In this case percolating pores in 4 to $8 \mathrm{~nm}$ range were obtained by combining polymerization-induced microphase separation and in situ block copolymer formation, with again the PLA block being finally etched to form the pores. 
(a)

Etching
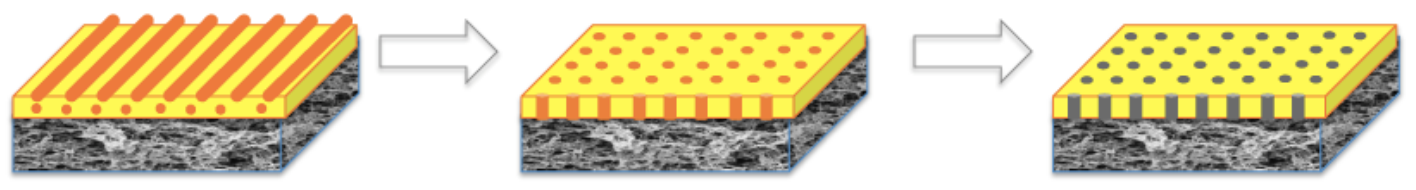

(b)
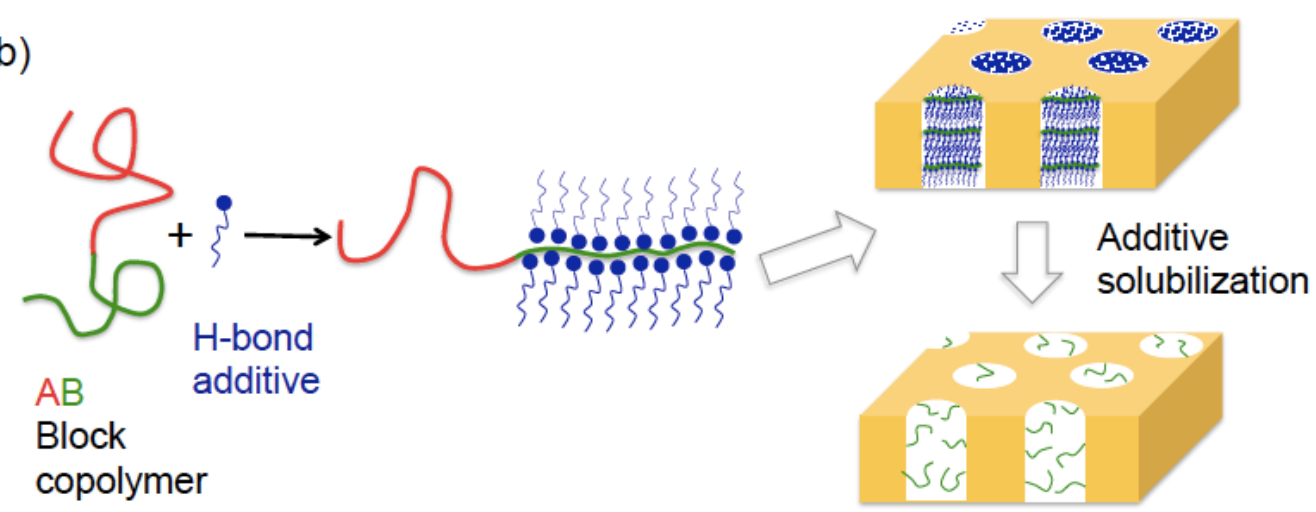

Figure 7. (a) Porous block copolymer membranes prepared by annealing and block sacrifice; (b) morphology induction by complexing additives, based on 133, 136, 137 .

Research perspectives for block copolymer membranes

The number of publications on block copolymer membranes (SNIPS and other methods) exponentially increased in the last years, as can be seen in Figure 8. After the first reports 110,111 on SNIPS block copolymers membranes, research related to this concept has actively grown ${ }^{61-63,99,100,113-115,117-119,138-151 .}$

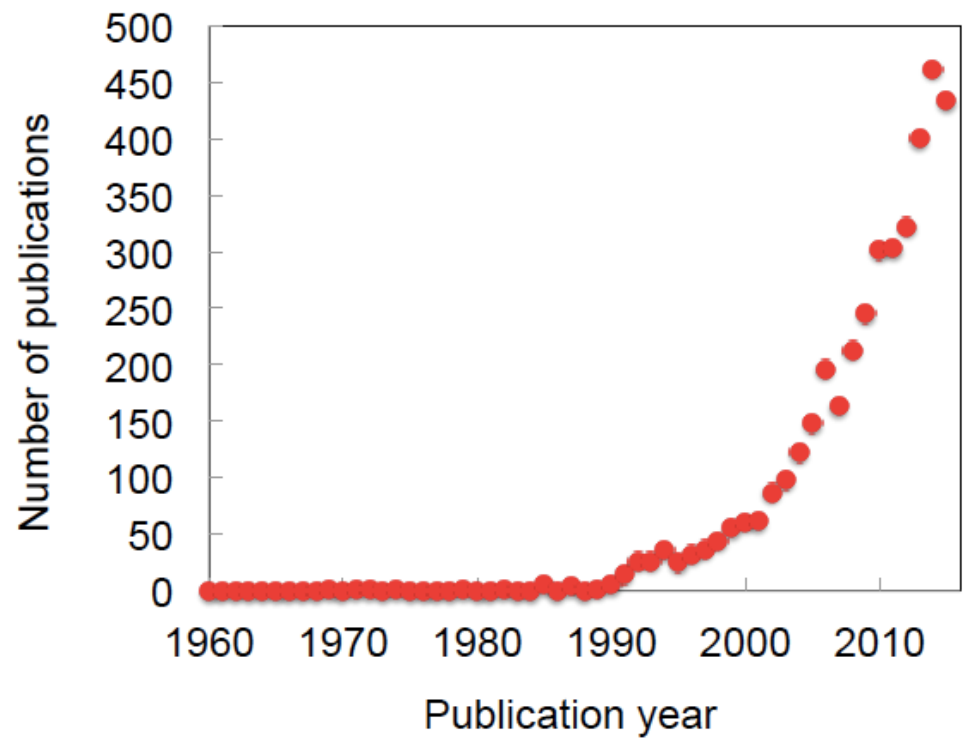


Figure 8. Increase of the number of publications on block copolymer membranes, according to Web of Science.

Many open questions and opportunities are there to be explored. Some will be mentioned here:

Mechanism disclosure. Structure formation in different membrane layers is now much better understood, but we believe that deeper investigation of the surface contribution is needed to confirm the mechanism discussed above for the SNIPS process. For SNIPS and other casting methods, more simulations in the semi-diluted regime are needed to fully predict the self-assembly in the solution bulk and the effect of different chemistry and conditions on the membrane preparation. The block copolymer assembly in the melt has been carefully investigated, predominantly using self-consistent field theory ${ }^{38}$. Much less has been done in the semi-dilute regime. We have been using dissipative particle dynamics (DPD) ${ }^{99,115,152}$ for simulations in this concentration range.

Hollow fiber and flat-sheet scale-up. A great advantage of the SNIPS process is the possibility of scaling-up the manufacture ${ }^{61,140}$, since the technology requires the same equipment currently used in the industry for the production of commercial asymmetrically porous membranes, continuous machines, casting polymer solutions on non-woven supports, which provide the needed mechanical stability. Additionally to the flat-sheet configuration, hollow fibers are frequently used in large membrane applications such as artificial kidney. The manufacture of block copolymer membranes in hollow fiber geometry has been demonstrated by our group ${ }^{138,139}$ and by Radjabian et al. ${ }^{146}$. In summary as long as the desired block copolymers is available with narrow molecular weight distribution in large amount and at reasonable cost scaling up is not a problem. We have demonstrated the preparation of double layer hollow fibers ${ }^{138}$, in which one layer is made of homopolymer and only a thin layer is constituted by the ordered assembled block copolymer responsible for high selectivity. For that a triple spinneret is needed, a technology implemented for homopolymer membranes. More research is required for optimization as well as the extension of the method to other copolymer and homopolymer systems. Multilayer membranes are possible as flat-sheet using a solvent resistant porous substrate. A different approach for upscale was recently reported by Hahn et al. ${ }^{151}$, exploring spray coating for depositing the block copolymer layer.

Copolymer chemistry. Most research on SNIPS-manufactured membranes used copolymers prepared by anionic polymerization, such as PS- $b$-P4VP, PS- $b$-PEO and PS$b$-poly (acrylic acid) (PS- $b$-PAA). Additionally to anionic polymerization a variety of copolymerization methods (e. g. click chemistry, ATRP, RAFT ${ }^{153}$ ) is available, easier to implement with acceptable polydispersity, allowing a diversification of the membrane composition. Most copolymers investigated so far for SNIPS and other methods have a PS block. Changing for instance to polysulfone would significantly improve the membrane stability. The main challenge for an effective preparation of polysulfone block copolymers is that a combination of synthetic methods would be needed (e. g. classical polycondensation and RAFT) and polydispersity might be compromised. New chemistry could further explore stimuli response. PS- $b$-P4VP and PS- $b$-PA respond to $\mathrm{pH}$. Pore size 
and surface charge change with $\mathrm{pH}$. By combining narrow pore size distribution and $\mathrm{pH}-$ response, membranes and porous particles have demonstrated to be selective for challenging protein separations ${ }^{61,63,142}$. P4VP and PAA could be substituted by blocks responsive to other stimuli after post-functionalization with additional segments analogously to what have been reported for track-etched membranes ${ }^{154}$, opening possibilities for membranes, which would be temperature (e. g. $\mathrm{N}$-isopropyl acrylamide blocks or poly(N,N-dimethylaminoethyl methacrylate ${ }^{155}$ ) or light responsive (azo- and spiro derivate blocks). An excellent review on stimuli-responsive polymeric materials was published by Stuart et al. ${ }^{156}$, guiding the choice of different chemistries. O'Reilly et al. ${ }^{157}$ and Rodriguez-Hernandez et al. ${ }^{158}$ have reported examples of multi-stimuli responsive block copolymer micelles stabilized by crosslinking for drug delivery application, which add additional levels of complexity if adapted for membranes.

Pore size. Most SNIPS-manufactured membranes have pores in the range of ultrafiltration $(20-70 \mathrm{~nm})$. Pore tuning is possible by changing the block sizes and consequently the size of the assemblies in solution ${ }^{149}$, but this strategy has a thermodynamic limitation, which makes the preparation of nanofiltration membranes by SNIPS hard to achieve. The reason is the following. As the block size decreases a condition might be achieved for which segregation is not expected anymore $\left(\chi_{\mathrm{AB}} \mathrm{N}\right.$ $<10.5)$. Therefore other strategies are needed. Radjabian et al. ${ }^{159}$ mixed copolymers of different block length with some pore size control, but the pores were not smaller than 20 $\mathrm{nm}$. The big challenge is to go down to much smaller pore sizes in the nanofiltration range. Post-chemical functionalization is an obvious possibility, which can reduce pore size and add a broad range of functionalities. Post modification by electroless gold deposition ${ }^{142}$ has been demonstrated to reduce the size to $3 \mathrm{~nm}$. Pore size can decrease by controlling $\mathrm{pH}$. Many of the reported block copolymer membranes contain P4VP or PAA segments. Low $\mathrm{pH}$ leads to protonation of P4VP blocks and high $\mathrm{pH}$ leads to deprotonation of PAA blocks. In both cases stretching of the hydrophilic segment results in pore size decrease in the swollen state. This effect has been well demonstrated for diblock- and triblock copolymers $61,63,100,153,160$. The minimum pore size depends on the length of the stretchable pH-responsive block and the size of the pre-formed pores. Membranes prepared from PS- $b$-P4VP $(138 \mathrm{k}-b-41 \mathrm{k} \mathrm{g} / \mathrm{mol})$ copolymers have pores as small as 1-3 nm, when swollen in low $\mathrm{pH}$. PI- $b$-PS- $b$-PAA copolymers have been synthesized and manufactured into membranes with minimum pore size of $3.4 \mathrm{~nm}{ }^{153}$ with permeability of $0.6 \mathrm{~L} \mathrm{~m}^{-2} \mathrm{~h}^{-1} \mathrm{bar}^{-1}$ at $\mathrm{pH}$ higher than 4 . At low $\mathrm{pH}$ the pore size increased and the permeability increased to $16 \mathrm{~L} \mathrm{~m}^{-2} \mathrm{~h}^{-1} \mathrm{bar}^{-1}$. Gu et al. ${ }^{160}$ used glycerol as additive to PI- $b$-PS- $b$-P4VP casting solution to increased the unswollen membrane pore size, which was then reduced to $5 \mathrm{~nm}$ when swollen in low $\mathrm{pH}$ with flux of $15 \mathrm{~L} \mathrm{~m}^{-2}$ $\mathrm{h}^{-1}$ bar $^{-1}$. At neutral $\mathrm{pH}$ for the same membrane the pores are open to $29 \mathrm{~nm}$ with flux increase to $400 \mathrm{~L} \mathrm{~m}^{-2} \mathrm{~h}^{-1}$ bar $^{-1}$. Recently ${ }^{115}$ we found out that by blending PS- $b$-P4VP with small molecular weight PS- $b$-PAA copolymers nanofiltration membranes could be obtained with pore size as small as $1.5 \mathrm{~nm}$, rejecting solutes of $600 \mathrm{~g} / \mathrm{mol}$ at neutral $\mathrm{pH}$ with remarkably high flux of $432 \mathrm{~L} \mathrm{~m}^{-2} \mathrm{~h}^{-1}$ bar ${ }^{-1}$. This was demonstrated for one blend system, but we anticipate that this approach would be successful with a variety of still unexplored copolymer compositions. 
Organic-inorganic hybrids and templates. The combination of block copolymers and inorganic materials can be explored in different forms. Fully metallic porous membranes were prepared by Wang et al. ${ }^{161}$, using PS- $b$-P2VP as template followed by gold electrodeposition. We used controlled electroless deposition of gold in different extents to reduce pore size ${ }^{142}$ of PS- $b$-P4VP membranes. When incorporated in small amounts in PS- $b$-P4VP hollow fibers, gold could be used as catalyst for reduction reactions of pnitrophenol ${ }^{139}$. Analogous incorporation of silver ${ }^{143}$ improved the biofouling resistance. Wiesner's group demonstrated that ${ }^{162}$ PI- $b$-PEO copolymer films could be used with (3glycidyloxypropyl) trimethoxysilane and aluminum-tri-sec-butoxide for the preparation of hybrid materials or as templates for metal oxide and carbon-platinum porous materials. Analogously graded porous carbon, metal and metal oxide asymmetric structures were prepared from PI- $b$-PS- $b$-P4VP self-assembly, as well as organic-inorganic membranes with $\mathrm{TiO}_{2}$ 163, 164. We recently combined block copolymers and metal-organicframeworks forming stimuli responsive systems for drug delivery ${ }^{141}$. These are some examples, which demonstrate the versatility of hybrid approaches.

Block etching and polymerization-induced phase separation. Block etching has been successfully explored in different forms to induce pore formation in membranes. The method recently proposed by Hillmyer's group based on a combination of polymerization-induced phase separation and in situ block copolymer formation 135,165 , 166, leading to preferential path for transport of further modifying by etching of PLA blocks to form the pores has a particular interest since it does not require the presynthesis of copolymers and allows immobilization of non-equilibrium morphologies achieved in solution if crosslinking is applied. More optimization and extension to other systems would be a valuable contribution. The incorporation of block copolymers into the IP layer ${ }^{134}$ has the advantage of forming very thin copolymer layers and has a potential of success extension to other systems.

\section{Final remarks}

In summary research on block copolymer membranes is exponentially growing with innumerous opportunities for new developments. We believe that the SNIPS process will be the one with fastest development and better chances of earlier industrial implementation since the process uses classical instrumentation of commercial membrane manufacture with innovative materials. Narrow pore size distribution can be obtained with many possibilities of functionalization and block combination. Optimization can be done based on knowledge acquired from homopolymer membrane manufacture. At the same time there are many opportunities to be explored, which are not possible with homopolymer membranes. It is hardly possible to manufacture membranes with the same level of porosity and narrow pore size distribution, which is obtained by using block copolymers. Track-etched membranes have a narrow pore size distribution, but the porosity is very low. Anopore inorganic membranes are isoporous with high porosity, but are very brittle and can not be manufactured and integrated in modules in a form comparable to polymeric membranes. SNIPS membranes are developed enough for use in the separation in the ultra- and nanofiltration range at room temperature and aqueous solutions at least in small scale. For applications in biomedical separations high level of 
reproducibility free of any defects is necessary and strict quality control in large scale is needed. The synthesis of copolymers with blocks other than polystyrene would improve the membrane resistance in more challenging operation conditions. New chemistry with tailored functionalities and specific stimuli response would extend the applications, having the membranes working as chemical gates for challenging separations, which are not possible with other available membranes. New hybrid systems are expected to substantially expand the possibilities of applications. The activities on polymerization induced phase separation are growing and innovative applications in the membrane field are expected.

\section{Acknowledgements}

The work on block copolymer membranes at the Nanostructured Polymeric Membranes Lab has been sponsored by the King Abdullah University of Science and Technology (KAUST), particularly by the URF/1/1671 CRG2 grant. The author thanks Prof. Klaus Peinemann, who introduced the idea of block copolymer membranes prepared by SNIPS, for constant and valuable discussions in this field, as well as our coworkers at KAUST dedicated to block copolymer research.

\section{References}

1. Lyman, D. J. ASAIO Journal 1963, 9, (1), 92-96.

2. Lyman, D. J.; Loo, B. H.; Crawford, R. W. Biochemistry 1964, 3, (7), 985-990.

3. Nunes, S. P.; Sforça, M. L.; Peinemann, K.-V. Journal of Membrane Science 1995, 106, (1), 49-56.

4. $\quad$ Yave, W.; Car, A.; Funari, S. S.; Nunes, S. P.; Peinemann, K.-V. Macromolecules 2009, 43, (1), 326-333.

5. Bondar, V.; Freeman, B.; Pinnau, I. Journal of Polymer Science Part B: Polymer Physics 1999, 37, (17), 2463-2475.

6. Boddeker, K. W.; Bengtson, G.; Pingel, H. Journal of Membrane Science 1990, 54, (1-2), 1-12.

7. Alvarez-Gallego, Y.; Ruffmann, B.; Silva, V.; Silva, H.; Lozano, A. E.; de la Campa, J. G.; Nunes, S. P.; de Abajo, J. Polymer 2008, 49, (18), 3875-3883.

8. Elabd, Y. A.; Hickner, M. A. Macromolecules 2011, 44, (1), 1-11.

9. $\quad$ Miyaki, Y.; Nagamatsu, H.; Iwata, M.; Ohkoshi, K.; Se, K.; Fujimoto, T. Macromolecules 1984, 17, (11), 2231-2236.

10. Ishizu, K.; Inagaki, K.; Fukutomi, T. Journal of Polymer Science: Polymer Chemistry Edition 1985, 23, (4), 1099-1108.

11. Kamachi, M.; Kurihara, M.; Stille, J. Macromolecules 1972, 5, (2), 161-167.

12. Kurihara, M.; Kamachi, M.; Stille, J. Journal of Polymer Science: Polymer Chemistry Edition 1973, 11, (3), 587-610.

13. Ishizu, K.; Murakami, A.; Fukutomi, T. Journal of Polymer Science Part A: Polymer Chemistry 1986, 24, (7), 1441-1454.

14. Liang, L.; Ying, S. Journal of Polymer Science Part B: Polymer Physics 1993, 31, (9), 1075-1081. 
15. Isono, Y.; Ito, H.; Hirahara, K.; Fujimoto, T.; Miyaki, Y. Journal of Membrane Science 1989, 43, (2-3), 205-216.

16. Geise, G. M.; Doherty, C. M.; Hill, A. J.; Freeman, B. D.; Paul, D. R. Journal of Membrane Science 2014, 453, 425-434.

17. Duong, P. H.; Chung, T.-S.; Wei, S.; Irish, L. Environmental science \& technology 2014, 48, (8), 4537-4545.

18. Laprade, E. J.; Liaw, C. Y.; Jiang, Z.; Shull, K. R. Journal of Polymer Science Part B: Polymer Physics 2015, 53, (1), 39-47.

19. Nunes, S. P.; Car, A. Industrial \& Engineering Chemistry Research 2012.

20. Dorn, J.; Belegrinou, S.; Kreiter, M.; Sinner, E. K.; Meier, W. Macromolecular bioscience 2011.

21. Kita-Tokarczyk, K.; Grumelard, J.; Haefele, T.; Meier, W. Polymer 2005, 46, (11), 3540-3563.

22. Kita-Tokarczyk, K.; Meier, W. CHIMIA International Journal for Chemistry 2008, 62, (10), 820-825.

23. Malinova, V.; Belegrinou, S.; de Bruyn Ouboter, D.; Meier, W. Polymer Membranes/Biomembranes 2010, 87-111.

24. Mecke, A.; Dittrich, C.; Meier, W. Soft Matter 2006, 2, (9), 751-759.

25. Tang, C.; Wang, Z.; Petrinić, I.; Fane, A. G.; Hélix-Nielsen, C. Desalination 2015, $368,89-105$.

26. Stoenescu, R.; Graff, A.; Meier, W. Macromolecular Bioscience 2004, 4, (10), 930-935.

27. Shen, Y.-X.; Saboe, P. O.; Sines, I. T.; Erbakan, M.; Kumar, M. Journal of

Membrane Science 2014, 454, 359-381.

28. Z Zhao, J.; Zhao, X.; Jiang, Z.; Li, Z.; Fan, X.; Zhu, J.; Wu, H.; Su, Y.; Yang, D.; Pan, F. Progress in Polymer Science 2014, 39, (9), 1668-1720.

29. Cho, Y.; Sundaram, H. S.; Weinman, C. J.; Paik, M. Y.; Dimitriou, M. D.; Finlay, J.

A.; Callow, M. E.; Callow, J. A.; Kramer, E. J.; Ober, C. K. Macromolecules 2011, 44, (12), 4783-4792.

30. Krishnan, S.; Ayothi, R.; Hexemer, A.; Finlay, J. A.; Sohn, K. E.; Perry, R.; Ober,

C. K.; Kramer, E. J.; Callow, M. E.; Callow, J. A. Langmuir 2006, 22, (11), 5075-5086.

31. Dimitriou, M. D.; Zhou, Z. K.; Yoo, H. S.; Killops, K. L.; Finlay, J. A.; Cone, G.;

Sundaram, H.; Lynd, N. A.; Barteau, K. P.; Campos, L. M. Langmuir 2011.

32. Meng, J.; Cao, Z.; Ni, L.; Zhang, Y.; Wang, X.; Zhang, X.; Liu, E. Journal of Membrane Science 2014, 461, 123-129.

33. Bengani, P.; Kou, Y.; Asatekin, A. Journal of Membrane Science 2015, 493, 755-

765.

34. Ye, G.; Lee, J.; Perreault, F.; Elimelech, M. ACS applied materials \& interfaces

2015.

35. Liu, Y.; Su, Y.; Li, Y.; Zhao, X.; Jiang, Z. RSC Advances 2015, 5, (27), 2134921359.

36. Leibler, L. Macromolecules 1980, 13, (6), 1602-1617.

37. Bates, F. S.; Fredrickson, G. H. Physics today 1999, 52, 32.

38. Bates, F. S.; Hillmyer, M. A.; Lodge, T. P.; Bates, C. M.; Delaney, K. T.;

Fredrickson, G. H. Science 2012, 434, 440.

39. Hamley, I. Progress in polymer science 2009, 34, (11), 1161-1210. 
40. Meuler, A. J.; Hillmyer, M. A.; Bates, F. S. Macromolecules 2009, 42, (19),

7221-7250.

41. Park, C.; Yoon, J.; Thomas, E. L. Polymer 2003, 44, (22), 6725-6760.

42. Matsen, M. W.; Bates, F. Macromolecules 1996, 29, (23), 7641-7644.

43. Ruzette, A. V.; Leibler, L. Nature materials 2005, 4, (1), 19-31.

44. Ruokolainen, J.; Saariaho, M.; Ikkala, O.; Ten Brinke, G.; Thomas, E.; Torkkeli, M.; Serimaa, R. Macromolecules 1999, 32, (4), 1152-1158.

45. Breiner, U.; Krappe, U.; Thomas, E. L.; Stadler, R. Macromolecules 1998, 31, (1), 135-141.

46. Shibayama, M.; Hasegawa, H.; Hashimoto, T.; Kawai, H. Macromolecules 1982, 15, (2), 274-280.

47. Matsushita, Y.; Yamada, K.; Hattori, T.; Fujimoto, T.; Sawada, Y.; Nagasawa, M.; Matsui, C. Macromolecules 1983, 16, (1), 10-13.

48. Mogi, Y.; Mori, K.; Matsushita, Y.; Noda, I. Macromolecules 1992, 25, (20), 5412-5415.

49. Shi, A.-C.; Li, B. Soft Matter 2013, 9, (5), 1398-1413.

50. Yabu, H.; Higuchi, T.; Jinnai, H. Soft matter 2014, 10, (17), 2919-2931.

51. Matsen, M.; Bates, F. Macromolecules 1996, 29, (23), 7641-7644.

52. Winey, K. I.; Thomas, E. L.; Fetters, L. J. Macromolecules 1992, 25, (1), 422428.

53. Thomas, E. L.; Anderson, D. M.; Henkee, C. S.; Hoffman, D. Nature 1988, 334, 698-601.

54. Mogi, Y.; Nomura, M.; Kotsuji, H.; Ohnishi, K.; Matsushita, Y.; Noda, I. Macromolecules 1994, 27, (23), 6755-6760.

55. Avgeropoulos, A.; Dair, B. J.; Hadjichristidis, N.; Thomas, E. L. Macromolecules 1997, 30, (19), 5634-5642.

56. $\quad$ Erukhimovich, I.; Kriksin, Y. In Diamond-Forming Block Copolymers and

Diamond-like Morphologies: a New Route towards efficient Block Copolymer

Membranes?, APS Meeting Abstracts, 2014; 2014; p 19011.

57. Scriven, L. Nature 1976, 263, (5573), 123-125.

58. Thomas, E. L.; Alward, D. B.; Kinning, D. J.; Martin, D. C.; Handlin Jr, D. L.;

Fetters, L. J. Macromolecules 1986, 19, (8), 2197-2202.

59. Lipowsky, R. Nature 1991, 349, (6309), 475-481.

60. Battaglia, G.; Ryan, A. J. Nature Materials 2005, 4, (11), 869-876.

61. Nunes, S. P.; Behzad, A. R.; Hooghan, B.; Sougrat, R.; Karunakaran, M.; Pradeep, N.; Vainio, U.; Peinemann, K. V. ACS nano 2011, 5, (5), 3516-3522.

62. Nunes, S. P.; Karunakaran, M.; Pradeep, N.; He, H.; Behzad, A.; Hooghan, B.; Sougrat, R.; Peinemann, K. V. Langmuir 2011, 27, (16), 10184-10190.

63. Yu, H.; Qiu, X.; Nunes, S. P.; Peinemann, K.-V. Nature Communications 2014, 5.

64. Knoll, A.; Horvat, A.; Lyakhova, K.; Krausch, G.; Sevink, G.; Zvelindovsky, A.;

Magerle, R. Physical Review Letters 2002, 89, (3), 035501.

65. Knoll, A.; Magerle, R.; Krausch, G. The Journal of chemical physics 2004, 120, (2), 1105-1116.

66. Horvat, A.; Knoll, A.; Krausch, G.; Tsarkova, L.; Lyakhova, K.; Sevink, G.;

Zvelindovsky, A.; Magerle, R. Macromolecules 2007, 40, (19), 6930-6939. 
67. Ludwigs, S.; Böker, A.; Voronov, A.; Rehse, N.; Magerle, R.; Krausch, G. Nature materials 2003, 2, (11), 744-747.

68. Helfand, E. The Journal of Chemical Physics 1975, 62, (3), 999-1005.

69. Stewart-Sloan, C. R.; Thomas, E. L. European Polymer Journal 2011, 47, (4), 630-646.

70. Gido, S. P.; Schwark, D. W.; Thomas, E. L.; do Carmo Goncalves, M.

Macromolecules 1993, 26, (10), 2636-2640.

71. Li, W.; Liu, M.; Qiu, F.; Shi, A.-C. The Journal of Physical Chemistry B 2013, 117, (17), 5280-5288.

72. Huinink, H.; Brokken-Zijp, J.; Van Dijk, M.; Sevink, G. The Journal of Chemical Physics 2000, 112, (5), 2452-2462.

73. Ishige, R.; Higuchi, T.; Jiang, X.; Mita, K.; Ogawa, H.; Yokoyama, H.; Takahara, A.; Jinnai, H. Macromolecules 2015, 48, (8), 2697-2705.

74. Moughton, A. O.; Hillmyer, M. A.; Lodge, T. P. Macromolecules 2011, 45, (1), 2-

19.

75. Wang, Y.; Li, F. Advanced Materials 2011, 23, (19), 2134-2148.

76. Chi, P.; Wang, Z.; Li, B.; Shi, A.-C. Langmuir 2011, 27, (18), 11683-11689.

77. Albert, J. N.; Epps, T. H. Materials Today 2010, 13, (6), 24-33.

78. Nunes, S. P.; Peinemann, K.-V., Membrane technology: in the chemical industry. John Wiley \& Sons: 2006.

79. Mai, Y.; Eisenberg, A. Chemical Society Reviews 2012.

80. Luo, L.; Eisenberg, A. Langmuir 2001, 17, (22), 6804-6811.

81. Zhang, L.; Eisenberg, A. Polymers for Advanced Technologies 1998, 9, (10 11), 677-699.

82. McConnell, G. A.; Gast, A. P. Macromolecules 1997, 30, (3), 435-444.

83. McConnell, G. A.; Gast, A. P.; Huang, J. S.; Smith, S. D. Physical review letters 1993, 71, (13), 2102-2105.

84. McConnell, G. A.; Lin, M. Y.; Gast, A. P. Macromolecules 1995, 28, (20), 67546764.

85. Lodge, T. P.; Bang, J.; Li, Z.; Hillmyer, M. A.; Talmon, Y. Faraday discussions 2005, 128, 1-12.

86. Lodge, T. P.; Bang, J.; Park, M. J.; Char, K. Physical review letters 2004, 92, (14), 145501.

87. Hanley, K. J.; Lodge, T. P.; Huang, C. I. Macromolecules 2000, 33, (16), 59185931.

88. Israelachvili, J. N. 2011.

89. Hayward, R. C.; Pochan, D. J. Macromolecules 2010, 43, (8), 3577-3584.

90. Gröschel, A. H.; Müller, A. H. Nanoscale 2015, 7, (28), 11841-11876.

91. Blanazs, A.; Armes, S. P.; Ryan, A. J. Macromolecular Rapid Communications 2009, 30, (4 - 5), 267-277.

92. Blanazs, A.; Madsen, J.; Battaglia, G.; Ryan, A. J.; Armes, S. P. Journal of the American Chemical Society 2011, 133, (41), 16581-16587.

93. Smart, T.; Lomas, H.; Massignani, M.; Flores-Merino, M. V.; Perez, L. R.; Battaglia, G. Nano Today 2008, 3, (3-4), 38-46. 
94. Christian, D. A.; Tian, A.; Ellenbroek, W. G.; Levental, I.; Rajagopal, K.; Janmey, P. A.; Liu, A. J.; Baumgart, T.; Discher, D. E. Nature Materials 2009, 8, (10), 843-849.

95. Warren, N. J.; Armes, S. P. Journal of the American Chemical Society 2014, 136, (29), 10174-10185.

96. Charleux, B.; Delaittre, G.; Rieger, J.; D’Agosto, F. Macromolecules 2012, 45, (17), 6753-6765.

97. Derry, M. J.; Fielding, L. A.; Armes, S. P. Progress in Polymer Science 2016, 52, 1-18.

98. Loeb, S.; Sourirajan, S. Adv. Chem. Ser. 1961, 38, 117.

99. Marques, D. S.; Vainio, U.; Chaparro, N. M.; Calo, V. M.; Bezahd, A. R.; Pitera, J.

W.; Peinemann, K.-V.; Nunes, S. P. Soft Matter 2013, 9, (23), 5557-5564.

100. Qiu, X.; Yu, H.; Karunakaran, M.; Pradeep, N.; Nunes, S. P.; Peinemann, K.-V. ACS Nano 2012, 7, (1), 768-776.

101. Reuvers, A.; Smolders, C. Journal of membrane science 1987, 34, (1), 67-86.

102. Wijmans, J.; Rutten, H.; Smolders, C. Journal of Polymer Science: polymer physics edition 1985, 23, (9), 1941-1955.

103. Strathmann, H. Journal of membrane science 1981, 9, (1), 121-189.

104. Koros, W.; Fleming, G. Journal of Membrane Science 1993, 83, (1), 1-80.

105. Pinnau, I.; Koros, W. J. Journal of Polymer Science Part B: Polymer Physics 1993, 31, (4), 419-427.

106. Nunes, S. P.; Inoue, T. Journal of Membrane Science 1996, 111, (1), 93-103.

107. Maggioni, J. F.; Nunes, S. P.; Pires, A. T. N.; Eich, A.; Horst, R.; Wolf, B. Polymer 1998, 39, (21), 5133-5138.

108. Peinemann, K.-V.; Maggioni, J.; Nunes, S. Polymer 1998, 39, (15), 3411-3416.

109. Cahn, J. W. The Journal of Chemical Physics 1965, 42, (1), 93-99.

110. Peinemann, K. V.; Abetz, V.; Simon, P. F. W. Nature Materials 2007, 6, (12), 992-996.

111. Nunes, S. P.; Sougrat, R.; Hooghan, B.; Anjum, D. H.; Behzad, A. R.; Zhao, L.; Pradeep, N.; Pinnau, I.; Vainio, U.; Peinemann, K. V. Macromolecules 2010, 43, (19), 8079-8085.

112. Phillip, W. A.; Mika Dorin, R.; Werner, J.; Hoek, E. M. V.; Wiesner, U.; Elimelech, M. Nano Letters 2011.

113. Marques, D. S.; Dorin, R. M.; Wiesner, U.; Smilgies, D.-M.; Behzad, A. R.; Vainio, U.; Peinemann, K.-V.; Nunes, S. P. Polymer 2014, 55, (6), 1327-1332.

114. Dorin, R. M.; Marques, D. S.; Sai, H.; Vainio, U.; Phillip, W. A.; Peinemann, K. V.; Nunes, S. P.; Wiesner, U. ACS Macro Letters 2012, 1, (5), 614-617.

115. Yu, H.; Qiu, X.; Moreno, N.; Ma, Z.; Calo, V. M.; Nunes, S. P.; Peinemann, K. V. Angewandte Chemie International Edition 2015, 54, 13937-13941.

116. Stegelmeier, C.; Filiz, V.; Abetz, V.; Perlich, J.; Fery, A.; Ruckdeschel, P.;

Rosenfeldt, S.; Förster, S. Macromolecules 2014, 47, (16), 5566-5577.

117. Madhavan, P.; Sougrat, R.; Behzad, A. R.; Peinemann, K.-V.; Nunes, S. P. Journal of Membrane Science $\mathbf{2 0 1 5 .}$

118. Oss-Ronen, L.; Schmidt, J.; Abetz, V.; Radulescu, A.; Cohen, Y.; Talmon, Y.

Macromolecules 2012, 45, (24), 9631-9642.

119. Madhavan, P.; Peinemann, K.-V.; Nunes, S. P. ACS applied materials \&

interfaces 2013, 5, (15), 7152-7159. 
120. Likos, C.; Harreis, H. Condensed Matter Physics 2002, 5, (29), 28.

121. Xie, Y.; Sougrat, R.; Nunes, S. P. Journal of Applied Polymer Science 2015, 132,

(5).

122. Munirasu, S.; Nunes, S. P. Journal of Materials Science 2014, 49, (21), 73997407.

123. McKenzie, B. E.; Friedrich, H.; Wirix, M. J.; de Visser, J. F.; Monaghan, O. R.; Bomans, P. H.; Nudelman, F.; Holder, S. J.; Sommerdijk, N. A. Angewandte Chemie 2015, 127, (8), 2487-2491.

124. Lee, J. S.; Hirao, A.; Nakahama, S. Macromolecules 1988, 21, (1), 274-276.

125. Lee, J. S.; Hirao, A.; Nakahama, S. Macromolecules 1989, 22, (6), 2602-2606.

126. Chen, S. Y.; Huang, Y.; Tsiang, R. C. C. Journal of Polymer Science Part A:

Polymer Chemistry 2008, 46, (6), 1964-1973.

127. Park, M.; Harrison, C.; Chaikin, P. M.; Register, R. A.; Adamson, D. H. Science 1997, 276, (5317), 1401-1404.

128. Park, S.; Wang, J. Y.; Kim, B.; Xu, J.; Russell, T. P. ACS nano 2008, 2, (4), 766-

772.

129. Thurn-Albrecht, T.; Steiner, R.; DeRouchey, J.; Stafford, C. M.; Huang, E.; Bal, M.; Tuominen, M.; Hawker, C. J.; Russell, T. P. Advanced Materials 2000, 12, (11), 787-791.

130. Phillip, W. A.; Hillmyer, M. A.; Cussler, E. Macromolecules 2010, 43, (18), 7763-7770.

131. Chen, L.; Phillip, W. A.; Cussler, E.; Hillmyer, M. A. Journal of the American Chemical Society 2007, 129, (45), 13786-13787.

132. Phillip, W. A.; O'Neill, B.; Rodwogin, M.; Hillmyer, M. A.; Cussler, E. ACS applied materials \& interfaces 2010, 2, (3), 847-853.

133. Jackson, E. A.; Hillmyer, M. A. ACS nano 2010, 4, (7), 3548-3553.

134. Seo, M.; Moll, D.; Silvis, C.; Roy, A.; Querelle, S.; Hillmyer, M. A. Industrial \& Engineering Chemistry Research 2014, 53, (48), 18575-18579.

135. Seo, M.; Hillmyer, M. A. Science 2012, 336, (6087), 1422-1425.

136. Liu, X.; Stamm, M. Nanoscale research letters 2009, 4, (5), 459-464.

137. Ikkala, O.; ten Brinke, G. science 2002, 295, (5564), 2407-2409.

138. Hilke, R.; Pradeep, N.; Behzad, A. R.; Nunes, S. P.; Peinemann, K.-V. Journal of Membrane Science 2014, 472, 39-44.

139. Hilke, R.; Pradeep, N.; Madhavan, P.; Vainio, U.; Behzad, A. R.; Sougrat, R.;

Nunes, S. P.; Peinemann, K.-V. ACS applied materials \& interfaces 2013, 5, (15), 70017006.

140. Nunes, S. P.; Behzad, A. R.; Peinemann, K.-V. Journal of Materials Research 2013, 28, (19), 2661-2665.

141. Yu, H.; Qiu, X.; Neelakanda, P.; Deng, L.; Khashab, N.; Nunes, S.; Peinemann, K. Scientific reports 2014, 5, 15275-15275.

142. Yu, H.; Qiu, X.; Nunes, S. P.; Peinemann, K. V. Angewandte Chemie 2014, 126, (38), 10236-10240.

143. Madhavan, P.; Hong, P.-Y.; Sougrat, R.; Nunes, S. P. ACS applied materials \& interfaces 2014, 6, (21), 18497-18501.

144. Pendergast, M. T. M.; Hoek, E. M. V. Energy Environ. Sci. 2011, 4, (6), 19461971. 
145. Quemener, D.; Bonniol, G.; Phan, T. N. T.; Gigmes, D.; Bertin, D.; Deratani, A. Macromolecules 2010, 43, (11), 5060-5065.

146. Radjabian, M.; Koll, J.; Buhr, K.; Handge, U. A.; Abetz, V. Polymer 2013.

147. Radjabian, M.; Koll, J.; Buhr, K.; Vainio, U.; Abetz, C.; Handge, U. A.; Abetz, V. Polymer 2014, 55, (13), 2986-2997.

148. Dorin, R. M.; Phillip, W. A.; Sai, H.; Werner, J.; Elimelech, M.; Wiesner, U. Polymer 2014, 55, (1), 347-353.

149. Karunakaran, M.; Nunes, S. P.; Qiu, X.; Yu, H.; Peinemann, K.-V. Journal of Membrane Science 2014, 453, 471-477.

150. Keskin, D.; Clodt, J. I.; Hahn, J.; Abetz, V.; Filiz, V. Langmuir 2014, 30, (29), 8907-8914.

151. Hahn, J.; Clodt, J. I.; Abetz, C.; Filiz, V.; Abetz, V. ACS applied materials \& interfaces 2015, 7, (38), 21130-21137.

152. Moreno, N.; Nunes, S. P.; Peinemann, K.-V.; Calo, V. M. Macromolecules 2015.

153. Mulvenna, R. A.; Weidman, J. L.; Jing, B.; Pople, J. A.; Zhu, Y.; Boudouris, B. W.;

Phillip, W. A. Journal of Membrane Science 2014, 470, 246-256.

154. Friebe, A.; Ulbricht, M. Macromolecules 2009, 42, (6), 1838-1848.

155. Schacher, F.; Ulbricht, M.; Muller, A. Advanced Functional Materials 2009, 19, (7), 1040-1045.

156. Stuart, M. A. C.; Huck, W. T.; Genzer, J.; Müller, M.; Ober, C.; Stamm, M.;

Sukhorukov, G. B.; Szleifer, I.; Tsukruk, V. V.; Urban, M. Nature materials 2010, 9, (2), 101-113.

157. O'Reilly, R. K.; Hawker, C. J.; Wooley, K. L. Chemical Society Reviews 2006, 35, (11), 1068-1083.

158. Rodriguez-Hernandez, J.; ChÈcot, F.; Gnanou, Y.; Lecommandoux, S. Progress in polymer science 2005, 30, (7), 691-724.

159. Radjabian, M.; Abetz, V. Advanced Materials 2015, 27, (2), 352-355.

160. Gu, Y.; Wiesner, U. Macromolecules 2015, 48, (17), 6153-6159.

161. Wang, Y.; He, C.; Xing, W.; Li, F.; Tong, L.; Chen, Z.; Liao, X.; Steinhart, M. Advanced Materials 2010, 22, (18), 2068-2072.

162. Hoheisel, T. N.; Hur, K.; Wiesner, U. B. Progress in Polymer Science 2015, 40, 3-32.

163. Gu, Y.; Werner, J. G.; Dorin, R. M.; Robbins, S. W.; Wiesner, U. Nanoscale 2015, 7, (13), 5826-5834.

164. Gu, Y.; Dorin, R. M.; Wiesner, U. Nano letters 2013, 13, (11), 5323-5328.

165. McIntosh, L. D.; Schulze, M. W.; Irwin, M. T.; Hillmyer, M. A.; Lodge, T. P. Macromolecules 2015, 48, (5), 1418-1428.

166. Saba, S. A.; Mousavi, M. P.; Bühlmann, P.; Hillmyer, M. A. Journal of the American Chemical Society 2015, 137, (28), 8896-8899. 
Block copolymer membranes for aqueous solution applications Suzana Pereira Nunes

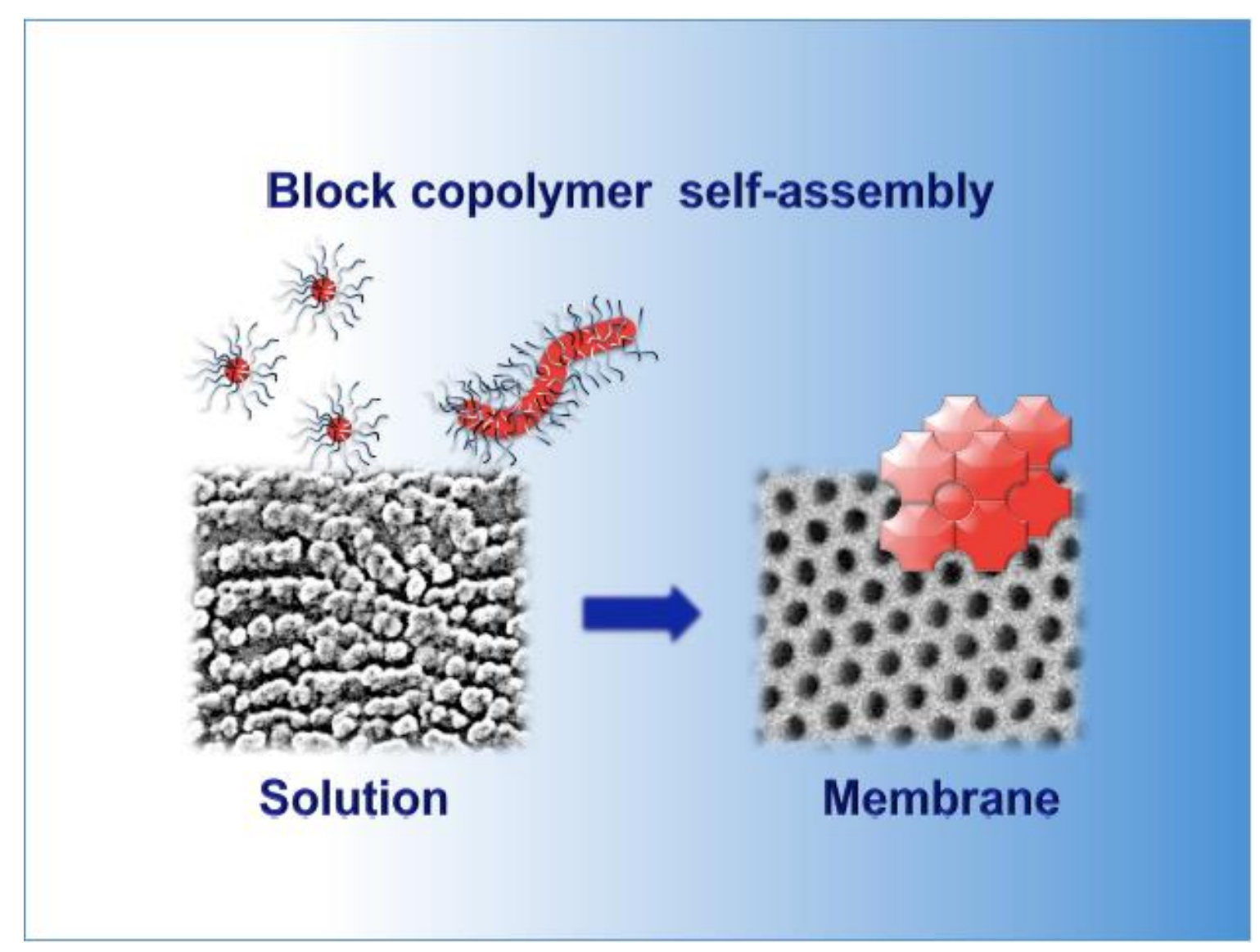




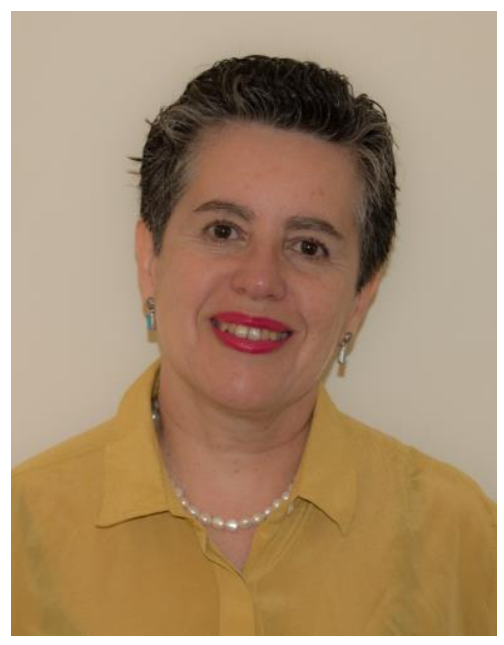

Biography

Suzana Nunes was born in Brazil, and received her $\mathrm{PhD}$ in Chemistry from the University of Campinas in 1985. She was a postdoc and Humboldt Fellow at the Johannes Gutenberg University in Mainz, Germany in 1985/1986, working on thermodynamics of polymer solutions. She was researcher at Pirelli Research Center, was Assistant and Associate Professor of Physical Chemistry at the University of Campinas in Brazil. In 1997 she joined the Helmholtz Research Center in Geesthacht, Germany, where she was head of the departments of Polymer Technology and of Membranes for Sustainable Energy. In 2009 she moved to the King Abdullah University of Science and Technology (KAUST) in Saudi Arabia, where she is now Professor of Environmental Science and Engineering and Associated Dean. She is Fellow of the Royal Chemical Society. Her research interests include the development of polymeric materials for membranes, morphology control and self-assembly of block copolymers in solutions. 